Chapter 8

\title{
Molecular Design of Soybean Lipoxygenase Inhibitors Based on Natural Products
}

\author{
Isao Kubo, Tae Joung Ha and Kuniyoshi Shimizu \\ Additional information is available at the end of the chapter
}

http://dx.doi.org/10.5772/52703

\section{Introduction}

Lipoxygenases (EC 1.13.11.12) are non-heme iron-containing enzymes that catalyze the site-specific oxygenation of polyunsaturated fatty acids to produce hydroperoxides. Lipoxygenases are suggested to be involved in the early event of atherosclerosis by inducing plasma low-density lipoprotein (LDL) oxidation [1, 2]. Lipoxygenase inhibitors have also been suggested to be potential cancer chemopreventives [3,4]. On the other hand, lipid peroxidation is well known as one of the major factors in deterioration during the storage and processing of foods, because it can lead to the development of unpleasant rancid or off flavors as well as potentially toxic end products [5]. Hence, lipoxygenase inhibitors should have broad applications [6].

Lipoxygenase inhibitors act in different ways; by chelating the iron of the active site of the enzyme $[7,8]$ and/or by reducing the ferric form of the enzyme to an inactive ferrous form $[9,10]$ (Fig. 1). Resorcinol exhibits no effect on this enzyme, indicating that the pentadeca(en)yl tail portion seemed an essential element in eliciting the inhibitory activity. The available information now demonstrates that lipoxygenase inhibitors can be designed when appropriate head portions are selected. 5-Pentadeca(en)yl salicylic acids, commonly known as anacardic acids, were previously reported to inhibit the linoleic acid (30) peroxidation catalyzed by soybean lipoxygenase-1 [11, 12]. This inhibition comes from chelating the iron of the active site of the enzyme but not by reducing the ferric form of the enzyme to an inactive ferrous form. In our structure and activity relationships (SAR) studies with lipoxygenase inhibitors, lipoxygenase inhibitors can be designed mainly by selecting appropriate head portions (See chemical structures, Fig. 2). Based on this concept, the experiment has been extended to search for lipioxygenase inhibitors acting both by chelating the iron of the active site of the enzyme and by reducing the ferric form of the enzyme to an inactive ferrous form. 


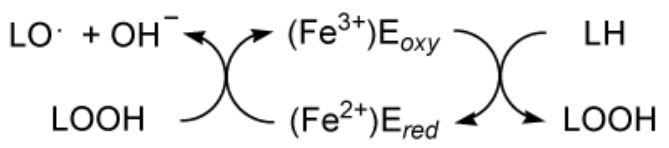

Figure 1. Commercial lipoxygenase contains a non-hemeferrous ion $\left(\mathrm{E}_{\mathrm{red}}\right)$ that must be oxidized to yield the catalytically active ferric enzyme $\left(\mathrm{E}_{\text {oxy }}\right)$ and therefore a catalytic amount of LOOH $(13-H P O D, 27)$ is usually added as a cofactor to LH (linoleic acid, a substrate, 30 ).

\section{Results}

To begin with, ethylenediaminetetraacetic acid (EDTA, 28), a well known chelate agent was tested butit did not show any lipoxygenase inhibitory activity, indicating that the chelation ability alone is not enough in eliciting the inhibitory activity. For example, it appears that hydrophilic ligands with a longer alkyl chain length tend to be more potent inhibitors. The molecular lipophilicity has a critical impact on the ability of this class of chelator to inhibit lipoxygenase. Nordihydroguaiuretic acid (NDGA, 26) is known to inhibit lipoxygenase by reducing the ferric form of the enzyme to an inactive ferrous form but not by chelating the iron of the active site of the enzyme. Hence, various phenolic acids were first tested for their radical scavenging activity using 1,1-diphenyl-2-picrylhydrazyl (DPPH, 29). This activity can be measured as decolorizing activity following the trapping of the unpaired electron of DPPH. In general, DPPH radical scavenging activity does not take into account the reaction time, and hence, the activity was first observed to be $20 \mathrm{~min}$ and then extended to $24 \mathrm{~h}$ for comparison. In preliminary experiments, their hexyl, nonyl and dodecyl (lauryl) esters were tested to see if the alkyl group affects scavenging activity. All the esters tested regardless of their alkyl chain length, scavenged six molecules of DPPH. In addition, one molecule of alkyl protocatechuates, regardless of their alkyl chain length, scavenges six molecules of DPPH radical and the alkyl chain length is not associated with the scavenging activity. Thus, alkyl protocatechuatesare oxidized three times by DPPH within $20 \mathrm{~min}$. The scavenging activity does not correlate with the hydrophobic alkyl chain length. This is consistent with the previous report with alkyl gallates $[13,14]$. Hence, all the alkyl protocatechuates can be used as scavenging antioxidants and selection of the tail portion is flexible. Alkyl protocatechuates can be expected to inhibit lipoxygenase by chelating the iron of the active site of theenzyme and by reducing the ferric form of the enzyme to an inactive ferrous form. Both 2,3-dihydroxybenzoic acid (24) and 2,5-dihydroxybenzoic acid (25) are known to scavenge DPPH [15]. In addition to their hexyl, nonyl and dodecyl esters, the same esters of 3,4dihydroxyphenyl alkanoates and 2,3-dihydroxyphenyl alkanoates were synthesized and tested for their effect on DPPH. All the esters tested, regardless of their alkyl chain length, were found to scavenge DPPH radicals. In a preliminary test, a series of alkyl 2,3-dihydroxybenzoates and 3,4-dihydroxybenzoates also scavenge DPPH.In addition, 2,3- and 3,4-dihydroxybenzoic acids(24 and $\mathbf{2 3}$ ) were previously reported to interact with Fe(II) and inhibit iron-induced oxidative DNA damage [16]. 


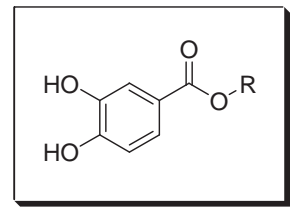

1: $\mathrm{R}=\mathrm{CH}_{2} \mathrm{CH}_{2} \mathrm{CH}_{3}$

2: $\mathrm{R}=\mathrm{CH}_{2}\left(\mathrm{CH}_{2}\right)_{4} \mathrm{CH}_{3}$

3: $\mathrm{R}=\mathrm{CH}_{2}\left(\mathrm{CH}_{2}\right)_{6} \mathrm{CH}_{3}$

4: $\mathrm{R}=\mathrm{CH}_{2}\left(\mathrm{CH}_{2}\right)_{7} \mathrm{CH}_{3}$

5: $\mathrm{R}=\mathrm{CH}_{2}\left(\mathrm{CH}_{2}\right)_{8} \mathrm{CH}_{3}$

6: $\mathrm{R}=\mathrm{CH}_{2}\left(\mathrm{CH}_{2}\right)_{9} \mathrm{CH}_{3}$

7: $\mathrm{R}=\mathrm{CH}_{2}\left(\mathrm{CH}_{2}\right)_{10} \mathrm{CH}_{3}$

15:<smiles>CCCCCc1cccc(O)c1C(=O)O</smiles>

8: $\mathrm{R}=\mathrm{CH}_{2}\left(\mathrm{CH}_{2}\right)_{12} \mathrm{CH}_{3}$

9: $\mathrm{R}=\mathrm{CH}_{2}\left(\mathrm{CH}_{2}\right)_{14} \mathrm{CH}_{3}$

10: $\mathrm{R}=\mathrm{CH}_{2}\left(\mathrm{CH}_{2}\right){ }_{16} \mathrm{CH}_{3}$<smiles>CC(C)=CCC/C(C)=C/CC=P</smiles>

12: $\mathrm{R}=$<smiles>[CH-]C1CCC2CCCCC2C1</smiles>

13: $\mathrm{R}=$<smiles>CC1(C)C2CC(F)C1(C)C2(C)C</smiles>

14:<smiles>CCCCCOC(=O)c1cccc(O)c1O</smiles>

32:<smiles>CCCCCC(=O)Oc1ccc(O)c(O)c1</smiles><smiles>[R]c1cc(C(=O)OCCCC)cc(Br)c1[R]</smiles>

19:<smiles>CCCCCCOC(=O)/C=C/c1ccc(O)c(O)c1</smiles>

31:

16: $\mathrm{R}_{1}: \mathrm{OH}, \mathrm{R}_{2}: \mathrm{OH}, \mathrm{R}_{3}: \mathrm{OH}$

17: $\mathrm{R}_{1}: \mathrm{OH}, \mathrm{R}_{2}: \mathrm{H}, \mathrm{R}_{3}: \mathrm{OH}$

18: $\mathrm{R}_{1}: \mathrm{OH}, \mathrm{R}_{2}: \mathrm{OH}, \mathrm{R}_{3}: \mathrm{OCH}_{3}$
20: $R_{1}: H, R_{2}: O H, R_{3}: H$

21: $\mathrm{R}_{1}: \mathrm{OH}, \mathrm{R}_{2}: \mathrm{H}, \mathrm{R}_{3}: \mathrm{H}$<smiles>CCCCCCOC(=O)c1cc(O)c(O)c(O)c1</smiles>

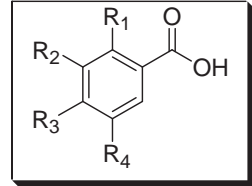

26:<smiles>CC(Cc1ccc(O)c(O)c1)C(C)Cc1ccc(O)c(O)c1</smiles>

27:<smiles>CCCCC[C@H](/C=C/C=C/CCCCCCCC(=O)O)OO</smiles>

30:<smiles>CCCC(=O)O</smiles>

22: $\mathrm{R}_{1}: \mathrm{H}, \mathrm{R}_{2}: \mathrm{OH}, \mathrm{R}_{3}: \mathrm{OH}, \mathrm{R}_{4}: \mathrm{OH}$

23: $\mathrm{R}_{1}: \mathrm{H}, \mathrm{R}_{2}: \mathrm{OH}, \mathrm{R}_{3}: \mathrm{OH}, \mathrm{R}_{4}: \mathrm{H}$ ŌOH

33: $\mathrm{OH}$
35:<smiles>Oc1ccccc1O</smiles>

24: $\mathrm{R}_{1}: \mathrm{OH}, \mathrm{R}_{2}: \mathrm{OH}, \mathrm{R}_{3}: \mathrm{H}, \mathrm{R}_{4}: \mathrm{H}$

25: $\mathrm{R}_{1}: \mathrm{OH}, \mathrm{R}_{2}: \mathrm{H}, \mathrm{R}_{3}: \mathrm{H}, \mathrm{R}_{4}: \mathrm{OH}$

28:<smiles>O=C(O)CN(CCN(CC(=O)O)CC(=O)O)CC(=O)O</smiles>

29:<smiles>O=[N+]([O-])c1cc([N+](=O)[O-])c(N(c2ccccc2)N(c2ccccc2)c2ccccc2)c([N+](=O)[O-])c1</smiles>

34:<smiles>O=c1cccc2cc(O)c(O)c(O)c2c1O</smiles>

Figure 2. Chemical structures. 
A homologous series of alkyl $\left(\mathrm{C}_{1}-\mathrm{C}_{20}\right)$ protocatechuates (3,4-dihydroxybenzoates) and their related derivatives were previously synthesized by one-step esterification utilizing DCC $\left(N, N^{\prime}\right.$ dicyclohexylcarbodiimide) as an activating agent [17]. The head and tail structures are synthetically easily accessible as esters and therefore the construction of a wide range of structurally diverse multifunctional mimics are available for evaluation. Thus, there are unlimited choices from common natural products for both head and tail portions. In contrast to their DPPH scavenging activity, the lipoxygenase inhibitory activity of alkyl protocatechuates was found to correlate with their alkyl chain lengths and require a certain head portion. This indicates that lipoxygenase inhibitors can be designed when appropriate head portions are selected.

The synthesized alkyl protocatechuates (Fig. 2)were tested for their effects on the soybean lipoxygenase-1 catalyzed oxidation of linoleic acid (30). Results are listed in Table 1. It appears that the inhibitory activity of alkyl protocatechuates was a parabolic function of their lipophilicity and maximized with alkyl chain lengths between $\mathrm{C}_{12}$ and $\mathrm{C}_{14}$. Among the compounds tested, tetradecanyl $\left(\mathrm{C}_{14}\right)$ protocatechuate $(8)$ showed the most potent inhibition with the concentration leading to $50 \%$ activity loss $\left(\mathrm{IC}_{50}\right)$ of $0.05 \mu \mathrm{M}$, followed by dodecyl $\left(\mathrm{C}_{12}\right)$ protocatechuate $(7)$ with an $\mathrm{IC}_{50}$ of $0.06 \mu \mathrm{M}$. On the other hand, their parent compounds, protocatechuic acid did not show any activity up to $200 \mu \mathrm{M}$, indicating that the alkyl chain was an essential element in eliciting the inhibitory activity. It thus appears that hydrophilic ligands with a longer alkyl chain length up to $C_{16}$ tend to be the more potent inhibitors. Since their head portions are the same, the data are interpreted to mean that changes in the hydrophobic tail portions correlated to the activity. Apparently a small change in chemical structure affects activity to a large extent.

\begin{tabular}{cccc}
\hline Compounds & $\mathbf{I C}_{50}(\boldsymbol{\mu M})$ & Inhibition Type & $\boldsymbol{K}_{i}(\boldsymbol{\mu M})$ \\
\hline $\mathbf{1}\left(C_{3}\right)$ & 39.4 & Competitive & 19.7 \\
$\mathbf{2}\left(C_{6}\right)$ & 2.3 & Competitive & 0.98 \\
$\mathbf{3}\left(C_{8}\right)$ & 0.55 & Competitive & 0.23 \\
$\mathbf{4}\left(C_{9}\right)$ & 0.25 & - & - \\
$\mathbf{5}\left(C_{10}\right)$ & 0.15 & - & - \\
$\mathbf{6}\left(C_{11}\right)$ & 0.09 & - & - \\
$\mathbf{7}\left(C_{12}\right)$ & 0.06 & Slow-binding & - \\
$\mathbf{8}\left(C_{14}\right)$ & 0.05 & - & - \\
$\mathbf{9}\left(C_{16}\right)$ & 0.31 & - & - \\
$\mathbf{1 0}\left(C_{18}\right)$ & 0.42 & - & - \\
$\mathbf{1 1}($ Geranyl) & 0.32 & - & - \\
$\mathbf{1 2}$ (Decahydro-2-naphthyl) & 0.1 & Slow-binding & - \\
$\mathbf{1 3}$ (Bornyl) & 0.09 & - & - \\
$\mathbf{1 4}$ & $>100$ & & - \\
\hline
\end{tabular}

- Not tested.

Table 1. $I C_{50}$ and $K_{\mathrm{i}}$ values and inhibition type of alkyl protocatechuates against soybean lipoxygenase-1 
The inhibitory activity of soybean lipoxygenase- 1 was measured by two methods for comparison, because this enzyme seems to be sensitive to assay conditions. In the current study, linoleic acid (30) was used as a substrate. Soybean lipoxygenase-1 is known to catalyze the dioxygenation of the $(1 Z, 4 Z)$-pentadiene moiety of linoleic acid (30). In plants, the primary dioxygenation product is 13(S)-hydroperoxy-9Z,11E-octadienoic acid (13-HPOD, 27) [18]. Hence, the enzyme assay was usually performed using a UV spectrophotometer to detect the increase at $234 \mathrm{~nm}$ associated with the $(2 Z, 4 E)$-conjugated double bonds newly formed in the product but not in the substrate. In previous reports, the data were obtained at $\mathrm{pH} 9$ since soybean lipoxygenase-1 has its optimum activity at $\mathrm{pH} 9.0$ [19], but the absorption at $234 \mathrm{~nm}$ suffered from unstable baseline activity of unknown origin attributable to the presence of the linoleic acid (30) substrate. This pseudoactivity of the blank control had to be substracted from activity of the enzyme assay, making precise measurements difficult. Moreover, this basic $\mathrm{pH}$ value may not be practical to use for food protection. Since the stable data were obtained at $\mathrm{pH}$ 8.0, the evaluation was performed at $\mathrm{pH} 8.0$ [20]. This was also compared with that of NADG (26) used as a reference compound. Its $\mathrm{IC}_{50}$ was obtained as $82 \mu \mathrm{M}$ when the experiment was performed at $\mathrm{pH} 9.0$ but $0.2 \mu \mathrm{M}$ at $\mathrm{pH}$ 8.0. As a result, octyl protocatechuate(3,4-dihydroxybenzoate) (3) showed a dose-dependent inhibitory effect on this oxidation as shown in Figure 3. As the concentration of octyl protocatechuate (3) increased, the enzyme activity was rapidly decreased with eventual complete suppression. The inhibitory concentration leading to $50 \%$ activity loss $\left(\mathrm{IC}_{50}\right)$ was estimated to be $0.55 \mu \mathrm{M}$. As the need arises, the assay was also monitored by using polarography (oxygen consumption) for comparison. The $\mathrm{IC}_{50}$ of octyl protocatechuate (3) obtained was $1.53 \mu \mathrm{M}$, which is almost comparable with that measured by the spectrophotometric method. The difference of $\mathrm{IC}_{50}$ values of these methods is due to a $K_{\mathrm{m}}$ for linoleic acid (30) almost 3-fold larger than using the oxygen monitor. This is in good agreement with previously reported observations [20,21].

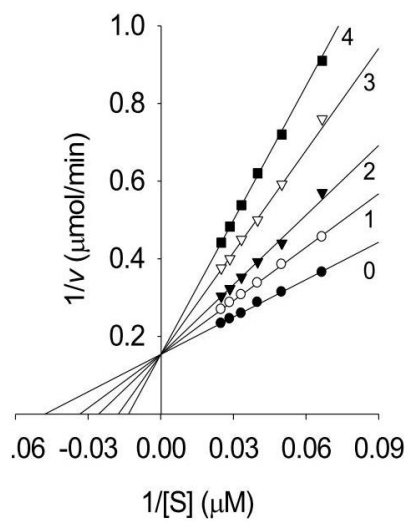

Figure 3. Lineweaver-Burk plots of 13-HPOD (27) generation by soybean lipoxygenase-1 in the presence of octyl protocathechuate $(3)$ at $25^{\circ} \mathrm{C}, \mathrm{pH} 8.0$. Concentrations of octyl protocathechuate (3) for curves $0-4$ were $0,0.1,0.2,0.4$, and $0.6 \mu \mathrm{M}$, respectively. 
Subsequently, the inhibition kinetics of soybean lipoxygenase-1 by octyl protocatechuate (3) was investigated as the representative molecule. The kinetic behavior of soybean lipoxygenase-1 during the oxidation of linoleic acid (30) was studied first. Under the conditions employed in the present investigation, the oxidation of linoleic acid (30) catalyzed by soybean lipoxygenase-1 follows Michaelis-Menten kinetics. The kinetic parameters for this oxidase obtained from a Lineweaver-Burk plot show that $K_{\mathrm{m}}$ is equal to $20.9 \mu \mathrm{M}$ and $V_{\max }$ is equal to $6.5 \mu \mathrm{mol} / \mathrm{min}$. The estimated value of $K_{\mathrm{m}}$ obtained with a spectrophotometric method is in good agreement with the previously reported value $(20,21)$. As illustrated in Figure 3, the inhibition kinetics analyzed by Lineweaver-Burk plots show that octyl protocatechuate (3) is a competitive inhibitor because increasing octyl protocatechuate (3) resulted in a family of lines with a common intercept on the $1 / v$ axis but with different slopes. This may suggest that octyl protocatechuate (3) displaces linoleic acid (30) from the enzymatic site of oxidation. The equilibrium constant for inhibitor binding, $K_{\mathrm{I}}$, was obtained from a plot of the apparent Michaelis-Menten constant versus the concentration of octyl protocatechuate (3), which is linear.
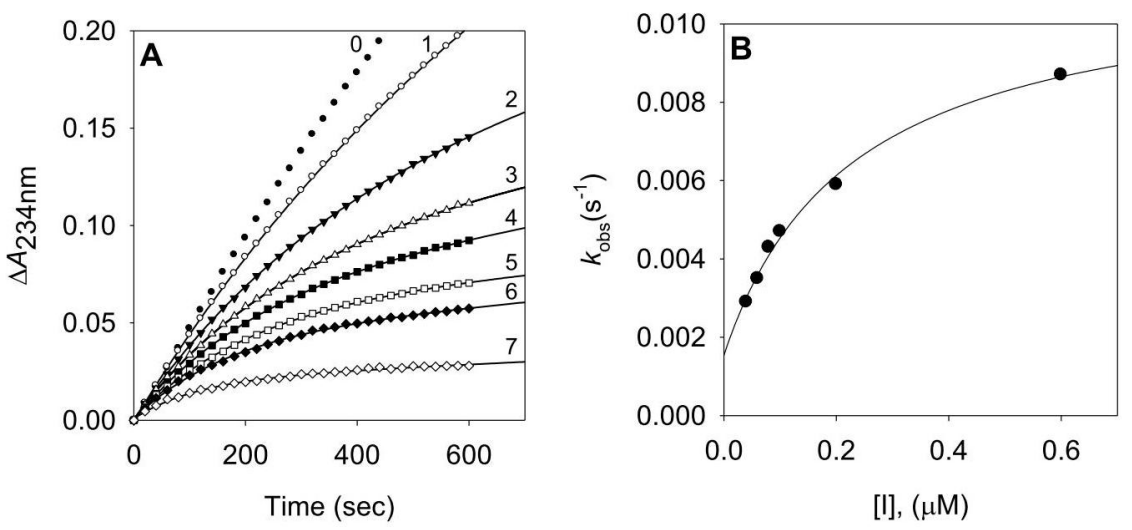

Figure 4. Time-dependent inhibition of soybean lipoxygenase-1 in the presence of dodecyl protocathechuate (7). (A) Conditions were as follows: $40 \mu \mathrm{M}$ linoleic acid (30), $1.3 \mathrm{nM}$ lipoxygenase-1, and concentrations of dodecyl protocathechuate (7) for curves $0-7$ were $0,0.02,0.04,0.06,0.08,0.1,0.2$, and $0.6 \mu \mathrm{M}$, respectively. The $k_{\text {obs }}$ values at each inhibitor concentration were determined. (B) Dependence of the values for $k_{\text {obs }}$ on the concentration of dodecyl protocathechuate (7). The $k_{\text {obs }}$ values, determined on panel A

To investigate the inhibitory effect of dodecyl protocatechuate (7) on dioxygenase enzyme, we assayed soybean lipoxygenase- 1 activity with the inhibitor. Soybean lipoxygenase- 1 showed time-dependent inhibition in the presence of dodecyl protocatechuate (7) (Figure 4, panel A). Increasing dodecyl protocatechuate (7) concentrations led to the decrease in both the initial velocity $\left(v_{\mathrm{i}}\right)$ and the steady-state rate $\left(v_{\mathrm{s}}\right)$ in the progress curve. The progress curves obtained using various concentrations of the inhibitors were fitted to eq 1 to determine $v_{\mathrm{i}}, v_{\mathrm{s}}$, and $k_{\mathrm{obs}}$.

$$
A=v_{s} t+\left(v_{i}-v_{s}\right)\left[1-\exp \left(-k_{o b s} t\right)\right] / k_{o b s}+A_{0}
$$


The plot for $k_{\mathrm{obs}}$ versus [I] are shown in panel B in Figure 4 . That plot showed a hyperbolic dependence on the concentration of the dodecyl protocatechuate (7), so the inhibition of lipoxygenase- 1 by dodecyl protocatechuate (7) followed mechanism A (Figure 5). The kinetic parameters, $k_{5}, k_{6}$, and $K_{\mathrm{i}}^{\mathrm{app}}$ were derived from the plots by fitting the results to following eq 2 .

$$
k_{o b s}=k_{6}+\left[\left(k_{5} \times[I]\right) /\left(K_{i}^{a p p}+[I]\right)\right.
$$

Thus, analysis of data yielded the following values: $k_{5}=9.8 \times 10^{-3} \mathrm{~s}^{-1}, k_{6}=1.5 \times 10^{-3} \mathrm{~s}^{-1}, K_{\mathrm{i}}^{\text {app }}=$ $0.23 \mu \mathrm{M}$.The kinetic model can be written as:

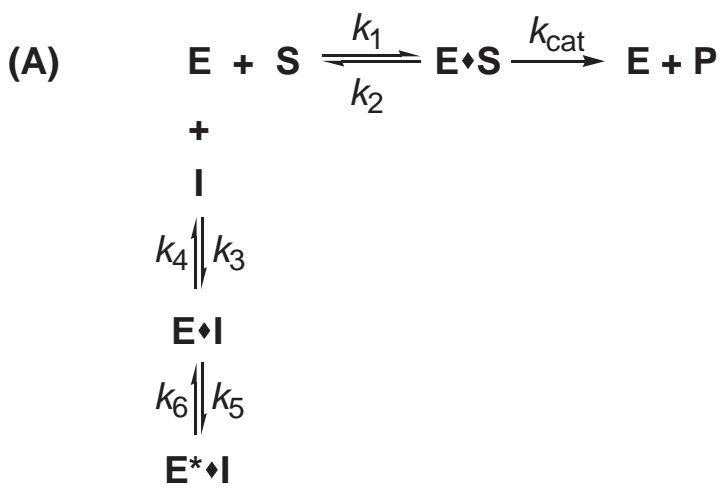

Figure 5. The kinetic model of mechanism A

where E, S, I, and P denote enzyme, substrate, inhibitor (dodecyl protocatechuate) (7) and product $(13-\mathrm{HPOD}, 27)$, respectively. ES and EI are respective complexes. Because $k_{5}$ is greater than $k_{6}$ the enzyme first quickly and reversibly binds with dodecyl protocatechuate (7) and then undergoes a slow interaction of dodecyl group with the hydrophobic portion near the active site. In the case of octyl protocatechuate (3) [14], conversely $k_{6}$ is greater than $k_{5}$, and hence, it was observed as a competitive inhibitor. The effect of dodecyl protocatechuate (7) on the soybean lipoxygenase-1 catalyzed oxidation of linoleic acid (30) is similar to octyl protocatechuate (3) in many aspects but different to some extents.

Subsequently, the progress curves of 13-HPOD (27) generation show thatdecahydro-2-naphthylprotocatechuate (12) also inhibited soybean lipoxygenase-1 by slow-binding inhibition mechanism A (Figure 5). The $k_{\text {obs }}$ values for the decahydro-2-napthyl protocatechuate (12) inhibition of lipoxygenase- 1 at different concentrations of decahydro-2-napthyl protocatechuate (12) were determined by fitting data to the slow-binding equation (eq1). The $k_{\mathrm{obs}}$ values were plotted as a function ofdecahydro-2-napthyl protocatechuate (12) concentration. The results indicated that decahydro-2-napthyl protocatechuate (12) inhibits soybean lipoxygenase- 1 by slow enzyme isomerization. This was evidenced by the observation that the $k_{\mathrm{obs}}$ values exhibited a hyperbolic dependence on the inhibitor concentration as shown in Figure 
6B. Thus, analysis of data according to eq2 yielded the following values: $k_{5}=8.8 \times 10^{-3} \mathrm{~s}^{-1}, k_{6}=$ $1.7 \times 10^{-3} \mathrm{~s}^{-1}, K_{\mathrm{i}}^{\mathrm{app}}=0.12 \mu \mathrm{M}$.
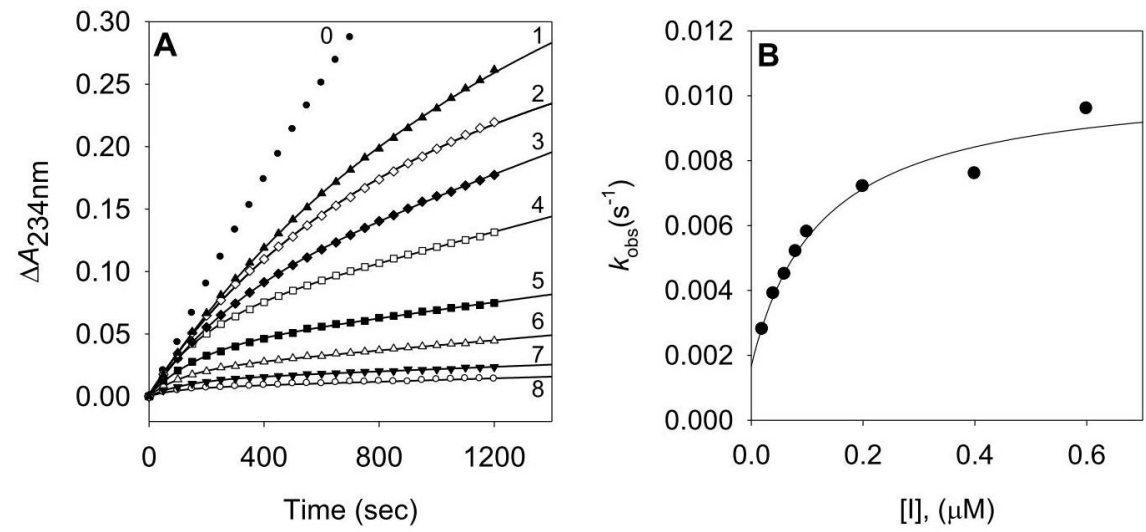

Figure 6. Time-dependent inhibition of soybean lipoxygenase-1 in the presence of decahydro-2-napthylprotocathechuate (12). Conditions were as follows: $40 \mu \mathrm{M}$ linoleic acid, $1.3 \mathrm{nM}$ lipoxygenase-1, and concentrations of decahydro-2-naphtyl protocathechuate for curves $0-8$ were $0,0.02,0.04,0.06,0.08,0.1,0.2,0.4$, and $0.6 \mu \mathrm{M}$, respectively. The $k_{\text {obs }}$ values at each inhibitor concentration were determined by fitting the data to eq1. (B) Dependence of the values for $k_{\mathrm{obs}}$ on the concentration of decahydro-2-naphtyl protocathechuate (12).

Soybean lipoxygenase-1 was used if dodecyl protocatechuate (7) inhibited the linoleic acid (30) peroxidation by this enzyme. The result is shown in Figure 4. Dodecyl protocatechuate (7) inhibited the linoleic acid (30) peroxidation $80 \%$ at $30 \mu \mathrm{g} / \mathrm{mL}(88.8 \mu \mathrm{M})$ and $\mathrm{IC}_{50}$ was established as $3.5 \mu \mathrm{g} / \mathrm{mL}(10.3 \mu \mathrm{M})$. Soybean lipoxygenase-1 inhibition mechanism of dodecyl protocatechuate (7) first competes with the active site, and then the hydrophobic dodecyl side chain interacts with the hydrophobic domain close to the active site in the enzyme. The inhibition of the enzyme by dodecyl protocatechuate (7) is a reversible reaction without residual activity. The hydrophobic interaction with the enzyme increases with increasing the alkyl chain length. The results imply that the inhibitory activity of soybean lipoxygenase-1 increases with increasing the alkyl chain length.

Some lipoxygenases reduce the ferric form of the enzyme to an inactive ferrous form $[9,10]$. This enzyme reduction mechanism is directly measurable by electron spin resonance(ESR)and fluorescence and also is indirectly observable when the inhibitor-dependent decrease in 13-HPOD (27) concentration, catalyzed by lipoxygenase-1, using the variation in $A_{234} \mathrm{~nm}$. Nordihydroguaiuretic acid (NDGA, 26) is a well known soybean lipoxygenase-1 inhibitor. It acts by reducing the catalytically active ferric enzyme to the catalytically inactive ferrous enzyme [9]. As a result, Figure 7 demonstrates the fast decrease in $A_{234}$, observed with addition of NDGA (26) in the pseudoperoxidase activity assay system. However, dodecyl protocatechuate (7) did not have a significant difference between controls. It should be noted that the inhibitor concentration used in this assay $(10 \mu \mathrm{M})$ was 150 -fold higher than the $\mathrm{IC}_{50}$ value for the inhibition of the lipoxygenase reaction. These results indicate that do- 
decyl protocatechuate (7) did not convert the catalytically active ferric form to the inactive ferrous form, despite the fact that dodecyl protocatechuate (7) inhibition potencies are within the range of those of reducing inhibitors.

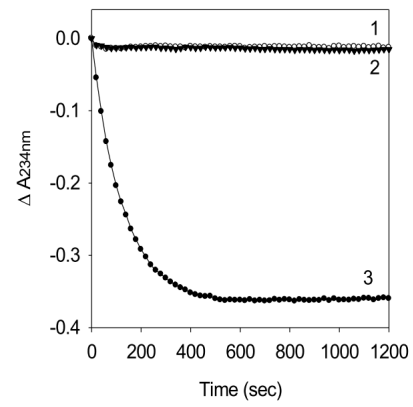

Figure 7. Effects of NDGA (26) and dodecyl protpcatechuate (7) on soybean lipoxygenase-1 catalyzed consumption of 13-HPOD (27). The conditions of incubation were 0 (1), $10 \mu \mathrm{M}$ dodecyl protocatechuate (2), and $10 \mu \mathrm{M}$ NDGA (3) with 13-HPOD $(15 \mu \mathrm{M}, 27)$ at $25^{\circ} \mathrm{C}$ in Tris-HCl buffer, $\mathrm{pH}$ 8.0. Dodecyl protocatechuate (7) did not reduce the catalytically active ferric form to the inactive ferrous form.

Since the head portion of alkyl protocatechuates is the same, the data are interpreted to mean that changes in the hydrophobic tail portions correlate and are responsible for this specific activity. As far as protocatechuic acid (23) is concerned, it remains the head portion. Their lipoxygenase inhibitory activity can be designed by selecting a side chain length to give the appropriate partition coefficient $(\log P)$ as a standard and the maximum activity was observed to be around 6. However, it should be noted that other factors are also possibly associated with the activity. For example, the introduction of branching or unsaturation into the hydrophobic moiety is known to increase the solubility of the molecules in water and consequently may be associated with the activity [23]. Since geranyl protocatechuate (11), decahydro-2-naphthyl protocatechuate (12) and bornylprotocatechuate (13) showed potent inhibitory activity, the hydrophobic portion can be flexible. In brief, the hydrophilic head moiety requires a certain specific structural feature but the hydrophobic tail portion is flexible. As mentioned earlier, the head and tail structures are synthetically easily accessible as esters and therefore the design of a wide range of structurally diverse lipoxygenase inhibitors can be available for evaluation. Thus, there are unlimited choices from common natural products for both head and tail portions. The target molecules can be designed using their $\log P$ values as a standard. Based on this concept, bornylprotocatechuate (13) was synthesized by connecting two common natural products, protocatechuic acid (23) and borneol, as an example. Thus, bornylprotocatechuate (13) inhibited the lipoxygenase-catalyzed peroxidation of linolenic acid (30) with an $\mathrm{IC}_{50}$ of $0.09 \mu \mathrm{M}$.

Based on the head and tail concept, octylgallate(3,4,5-trihydroxybenzoate) (31) [13] and dodecyl gallate (16) [14] were found to be potent lipoxygenase inhibitors. Since alkyl gallates are known to have iron binding properties, their galloyl moiety initially and rapidly binds with the active site as a chelator and then the alkyl group undergoes a slow interaction with 
the hydrophobic environment. The same head and tail concept has been extended to evaluate octylprotocatechuate (3) and dodecyl protocatechuate (7), and both were found to show even slightly more potent inhibitory activity than that of the corresponding alkyl gallates. On the other hand, dodecyl 3,5-dihydroxybenzoate (17) which does not have an ability to chelate ironwas alsoevaluated for comparison. This resorcinol derivative was also found to inhibitthe enzymatic linoleic acid (30) peroxidation, but to a much lesser extent compared to dodecyl gallate (16) or dodecyl protocatechuate (7). It appears that the activity of dodecyl gallate (16), which has the ability to chelate iron, is conspicuously potent. Compared to an acardic acid $\left(C_{15: 0}\right)(\mathbf{1 5})$, dodecylgallate (16) is nearly 200-fold more potent (Table 2). In the case of alky gallates, the hydrophilic ligands with a longer alkyl side chain of up to $C_{14}$ in length tend to be the more potent inhibitors [14]. Since their hydrophilic head portions are the same, the data are consequently interpreted to mean that changes in the hydrophobic tail portions correlated to the activity.On the one hand, dodecyl 3,4-dihydroxy-5-methoxybenzoate (18) still exhibited this inhibitory activity but to a much lesser extent compared to that of dodecyl gallate (16). This noticeable inferior activity can be explained by a steric hindrance to its approach to the active site in the enzyme, but dodecyl gallate (16) still reduces the ferric form of the enzyme to an inactive ferrous form. It would thus seem that a relatively small change in chemical structure of these molecules affects their biological activity to a large extent. The activity of alkyl 3,4-dihydroxybenzoates was compared with those of alkyl 2,3-dihydroxybenzoates, and thus the differences should be due to imply the hydrophilic head portions. Noticeably, dodecyl protocatechuate (7) showed potent lipoxygenase inhibitory activity with an $\mathrm{IC}_{50}$ value of $0.06 \mu \mathrm{M}$, whereas 3,4-dihydroxyphenyltridecanoate (32) also exhibited the inhibitory activity but to a much lesser extent. In these catechol (35) structures, the head and tail portions are connected as esters, either-COOR or -OCOR. Thus, the ester groups, either an electron withdrawing (-COOR) or an electron donating (-OCOR), were connected at the C-5 position to the catechol (35) moiety. The results obtained indicate that -COO Resters exhibited more potent inhibitory activity compared to the corresponding -OCOR esters, although the reason for this still remains obscure.

\begin{tabular}{lc}
\hline Compounds Tested & IC $_{\mathbf{5 0}}(\boldsymbol{\mu M})$ \\
\hline Anacardic acid $\left(\mathrm{C}_{15: 0}\right)(\mathbf{1 5})$ & 14.3 \\
Dodecyl 3,4,5-trihydroxybenzoate (16) & 0.07 \\
Dodecyl 3,5-dihydroxybenzoate (17) & 60.3 \\
Dodecyl 3,4-dihydroxy-5-methoxybenzoate (18) & 10.5 \\
Dodecyl 3,4-dihydroxycinnamate (19) & 3.3 \\
Dodecyl 4-hydroxybenzoate (20) & 200 \\
Dodecyl 3-hydroxybenzoate (21) & 200 \\
\hline
\end{tabular}

Table 2. Lipoxygenase-1 inhibitory related activity of selected compounds

The data obtained so far indicates that alkyl 3,4-dihydroxybenzoates can be expected as superior as lipoxygenase inhibitors similar to the alkyl 3,4,5-trihydroxybenzoates. It should be 
noted, however, that alkyl 3,4,5-trihydroxybenzoates were oxidized in part in basic condition. The lipoxygenase assay was performed using a UV spectrophotometer to detect the increase at $234 \mathrm{~nm}$ associated with the $(2 Z, 4 E)$-conjugated double bonds newly formed in the product but not the substrate. In previous reports, the data were obtained at $\mathrm{pH} 9$ since soybean lipoxygenase-1 had its optimum $\mathrm{pH}$ at 9.0 [19]. Alkyl 3,4,5-trihydroxybenzoates were oxidized in part at $\mathrm{pH} 9$ and therefore their data, obtained with the lipoxygenase inhibition,may not be their effects. Pyrogallol (1,2,3-benzentriol, 33) was previously described to react with dioxygen in weakly alkaline solution to form purpurogallin (2,3,4,6-tetrahydroxy-5H-benzocycloheptene-5-one, 34) [24]. Notably, alkyl gallates were oxidized in part at $\mathrm{pH} 9$ but alkyl protocatechuates were not.

The data obtained so far indicates that alkyl 3,4-dihydroxybenzoates can be expected as superior as lipoxygenase inhibitors similar to the alkyl 3,4,5-trihydroxybenzoates. It should be noted, however, that alkyl 3,4,5-trihydroxybenzoates were oxidized in part in basic condition. The lipoxygenase assay was performed using a UV spectrophotometer to detect the increase at $234 \mathrm{~nm}$ associated with the $(2 Z, 4 E)$-conjugated double bonds newly formed in the product but not the substrate. In previous reports, the data were obtained at $\mathrm{pH} 9$ since soybean lipoxygenase-1 had its optimum $\mathrm{pH}$ at 9.0 [19]. Alkyl 3,4,5-trihydroxybenzoates were oxidized in part at $\mathrm{pH} 9$ and therefore their data obtained with the lipoxygenase inhibition may not be their effects. The data obtained so far indicates that alkyl 3,4-dihydroxybenzoates can be expected as superiorlipoxygenase inhibitors. Hence, a series of alkyl 3,4-dihydroxybenzoates was assayed in detail for their effects on the linoleic acid (30) peroxidation catalysed by the soybean lipoxygenase- 1 .

In contrast to their DPPH scavenging activity, the lipoxygenase inhibitory activity of alkyl protocatechuates was found to correlate with their alkyl chain lengths and require a certain head portion. This indicates that lipoxygenase inhibitors can be designed when appropriate head portions are selected. For example, dodecyl 3,5-dihydroxybenzoate (17) exhibited any lipoxygenase inhibitory activity up to $200 \mu \mathrm{g} / \mathrm{mL}$.

\section{Discussion}

Alkyl protocatechuate antioxidants may act in a variety of ways including direct quenching of reactive oxygen species, inhibition of enzymes involved in the production of the reactive oxygen species, and chelation of low valent metal ions such as $\mathrm{Fe}^{2+}, \mathrm{Fe}^{3+}$ or $\mathrm{Cu}^{2+}$. In connection with this, both pyrogallol (33) and catechol (35) groups have iron binding properties in vitro. Alkyl gallates and protocatechuates may suppress the superoxide- driven Fenton reaction, which is currently believed to be the most important route to active oxygen species [25]. More specifically, alkyl gallates and protocatechuates may prevent cell damage induced by $\mathrm{H}_{2} \mathrm{O}_{2}$ since this can be converted to the more reactive oxygen species, hydroxy radicals, in the presence of these metal ions. Thus, metal chelation may play a large role in determining the antioxidant activity [26]. Interestingly, the inhibition of iron absorption in vivo has been positively correlated with the presence of galloyl groups but not catechol (35) groups [27]. 
Alkyl protocatechuates act as both lipoxygenase inhibitors and scavengers. Safety is a primary consideration for antioxidants in food products. After ingestion, the alkyl protocatechuates are likely hydrolyzed, at least in part, to protocatechuic acid and the corresponding alcohols that are common in edible plants. For example, pecan nuts contain protocatechuic acid as a one of predominant phenolic acids [28]. If alkyl protocatechuates can reach the sites where antioxidants are needed, a more lipophilic alkyl side chain may partition into lipophilic membranes of cells and organelles, where it presumably exerts its antioxidant activity, similar to the phytyl chain in tocopherols and tocotrienols [29]. The site of antioxidant location is known to be important, however, it is not clear if alkyl protocatechuates can reach, without being metabolized, the sites where antioxidants are needed for protection from oxidative damages. It should be noted, however, that the role of alkyl protocatechuates in the human body is unknown when orally ingested. It is not clear if alkyl protocatechuates are absorbed into the system through the intestinal tract and delivered to the places where lipoxygenase inhibitors are needed without being metabolized.

\section{Materials and methods}

Chemicals. A series of alkyl protocatechuates was available from our previous study [17].

Enzyme Assay. The assay was performed as previously reported [11]. The soybean lipoxygenase 1 (EC 1.13.11.12, Type I) used for the bioassay was purchased from Sigma Chemical Co. Linoleic acid (30) was used as a substrate. The reaction mixture consisted of $1.2 \mathrm{mM}$ linoleic acid (30), $60 \mathrm{mM}$ phosphate buffer ( $\mathrm{pH} 7.0)$ and different concentrations of sample. At zero time, the enzyme solution (100 units) was added to the reaction mixture. The lipoxygenase activity was measured polarographically with an oxygen electrode(YSI 53, Yellow Springs Instrument Co., Yellow Springs, $\mathrm{OH}$ ) at $25{ }^{\circ} \mathrm{C}$. Calibration of a Clark-type oxygen electrode was performed by using 4-tert-butylcatechol.The native enzyme is quite capable of producing 13-HPOD (27) directly from linoleic acid (30) without any prior activation.

\section{Acknowledgements}

The work was presented in part at the Symposium of Diet and the Prevention of Gender Related Cancers in Division of Agricultural and Food Chemistry for the 222nd ACS National Meeting in Chicago, Il.

\section{Abbreviations}

LDL, low-density lipoprotein; SAR, structure and activity relationships; NDGA, nordihydroguaiuretic acid; DPPH, 1,1-diphenyl-2-picrylhydrazyl; EDTA, ethylenediaminetetraace- 
tic acid; $\mathrm{IC}_{50^{\prime}}$ the half maximal inhibitory concentration; DCC, $N, N^{\prime}$ dicyclohexylcarbodiimide; gallic acid, 3,4,5-trihydroxybenzoic acid; gallate, 3,4,5trihydroxybenzoate; protocatechuic acid, 3,4-dihydroxybenzoic acid; protocatechuates, 3,4dihydroxybenzoate; 13-HPOD, 13(S)-hydroperoxy-9Z,11E-octadienoic acid; ESR, electron spin resonance; $K_{\mathrm{r}}$ inhibition constant; $K_{\mathrm{m}^{\prime}}$ Michaelis constant; $V_{\max }$ maximum velocity; $\log P$, partition coefficient

\section{Author details}

Isao Kubo, Tae Joung Ha and Kuniyoshi Shimizu

Department of Environmental Science, Policy and Management, University of California, Berkeley, California, USA

\section{References}

[1] Cornicelli JA, Trivedi BK. 15-Lipoxygenase and its Inhibition: a Novel Therapeutic Target for Vascular Disease. Current Pharmaceutical Design 1999;5(1) 11-20.

[2] Kris-Etherton PM, Keen CL. Evidence that the Antioxidant Flavonoids in Tea and Cocoa are Beneficial for Cardiovascular Health. Current Opinion in Lipidology. 2002;13(1):41-9.

[3] Steele VE, Holmes CA, Hawk ET, Kopelovich L, Lubet RA, Crowell JA, Sigman CC, Kelloff GJ. Lipoxygenase Inhibitors as Potential Cancer Chemopreventives. Cancer Epidemiology, Biomarkers \& Prevention. 1999;8(5):467-83.

[4] Fischer SM \& Klein RD. Lipoxygenases as Targets for Cancer Prevention. Totowa: Humana Press Inc; 2004

[5] Shibata D, Axelrod B. Plant Lipoxygenases. Journal of Lipid Mediators and Cell Signalling 1995; 12 (2-3): 213-228.

[6] Richard-Forget F, Gauillard F, Hugues M, Jean-Marc T, Boivin P, Nicolas J. Inhibition of Horse Bean and Germinated Barley Lipoxygenases by Some Phenolic Compounds. Journal of Food Science 1995; 60, 1325-1329.

[7] Clapp CH, Banerjee A, Rotenberg SA. Inhibition of Soybean Lipoxygenase 1 by n-Alkylhydroxylamines. Biochemistry 1985; 24, 1826-1830.

[8] Nelson MJ. Catecholate Complex of Ferric Soybean Lipoxygenase 1. Biochemistry $1988 ; 27,4273-4278$. 
[9] Kemal C, Louis-Flamberg P, Krupinski-Olsen R, Shorter A. Reductive Inactivation of Soybean Lipoxygenase-1 by Catechols: a Possible Mechanism for Regulation of Lipoxygenase Activity. Biochemistry 1987; 26 (22) 7064-7072

[10] Mansuy D, Cucurou C, Biatry B, Battioni JP. Soybean Lipoxygenase-catalyzed Oxidations by Linoleic Acid Hydroperoxide: Different Reducing Substrates and Dehydrogenation of Phenidone and BW 755C. Biochemical and Biophysical Research Communications 1988; 151, 339-346.

[11] Ha TJ, Kubo I. Lipoxygenase Inhibitory Activity of Anacardic Acids. Journal of Agricultural and Food Chemistry 2005; 53, 4350-4354.

[12] Kubo I, Ha TJ, Shimizu K, Lipoxygenase Inhibitory Activity of 6-Pentadecanylsalicylic Acid without Prooxidant Effect. Natural Product Communications 2010; 5 (1) 85-90

[13] Ha TJ, Nihei K, Kubo I, Lipoxygenase Inhibitory Activity of Octyl Gallate. Journal of Agricultural and Food Chemistry 2004; 52, 3177-3181.

[14] Ha TJ, Kubo I. Slow-binding Inhibition of Soybean Lipoxygenase-1 by Dodecyl Gallate. Journal of Agricultural and Food Chemistry 2007; 55, 446-451.

[15] Sroka Z, Cisowski W. Hydrogen Peroxide Scavenging, Antioxidant and Anti-radical Activity of Some Phenolic Acids. Food and Chemical Toxicology 2003; 42, 753-758.

[16] Lodovici M, Guglielmi F, Meoni M, Dolara P. Effect of Natural Phenolic Acids on DNA Oxidation In Vitro. Food and Chemical Toxicology 2001; 39(12) 1205-1210

[17] Nihei K, Nihei A, Kubo I. Rational Design of Antimicrobial Agents: Antifungal Activity of Alk(en)yl Dihydroxybenzoates and Dihydroxyphenyl Alkanoates. Bioorganic \& Medicinal Chemistry Letters 2003; 13, 3993-3996.

[18] Grechkin A. Recent Developments in Biochemistry of the Plant Lipoxygenase Pathway. Progress in Lipid Research 1998; 37(5) 317-52.

[19] Axelrod B, Cheesbrough TM, Laakso S. Lipoxygenase from Soybeans. Methods in Enzymology 1981; 71, 441-457.

[20] Berry H, Debat H, Larreta-Garde V. Excess Substrate Inhibition of Soybean Lipoxygenase-1 Is Mainly Oxygen-Dependent. FEBS Letters 1997;408(3) 324-6.

[21] Glickman MH, Klinman JP. Lipoxygenase Reaction Mechanism: Demonstration That Hydrogen Abstraction from Substrate Precedes Dioxygen Binding during Catalytic Turnover. Biochemistry, 1996, 35 (39) 12882-12892.

[22] Schilstra MJ, Veldink GA, Johannes JV, Vliegenthart FG. Effect of Lipid Hydroperoxide on Lipoxygenase Kinetics, Biochemistry 1992, 31 (33), 7692-7699

[23] Rosen MJ. Surfactants and Interfacial Phenomena, 2nd ed., New York: Wiley Interscience; pp. 1-32; 1989. 
[24] Abrash HI, Elias DSW, Malekmehr F. A Kinetic Study of the Air Oxidation of Pyrogallol and Purpurogallin. International Journal of Chemical Kinetics 1989; 21(6) 465476

[25] Afanas'ev IB, Dcrozhko AI, Brodskii AV, Kostyuk VA, Potapovitch AI. Chelating and Free Radical Scavenging Mechanisms of Inhibitory Action of Rutin and Quercetin in Lipid Peroxidation. Biochemical Pharmacology 1989; 38(11)1763-1769

[26] Arora A, Nair MG, Strasburg GM. Structure-activity Relationships for Antioxidant Activities of a Series of Flavonoids an a Liposomal System. Free Radical Biology and Medicine 1998; 24, 1355-1363.

[27] Brune M, Rossander L, Hallberg L. Iron Absorption and Phenolic Compound: Importance of Different Phenolic Structures. European Journal of Clinical Nutrition 1989; $43,547-558$.

[28] Senter SD, Horvat RJ, Forbus WRJ. Relation between Phenolic Acid Content and Stability of Pecans in Accelerated Storage. Journal of Food Science 1980; 45(5) 1380-1382.

[29] Burton GW, Joyce A, Ingold KU. Is Vitamin E the Only Lipid-soluble, Chain-breaking Antioxidant in Human Blood Plasma and Erythrocyte Membranes? Archives of Biochemistry and Biophysics 1983; 221(1) 281-90 
